\title{
Influence of Acetone and Sodium Chloride Additives on Cooling Efficiency of Water Droplets Impinging onto Hot Metal Surfaces
}

\author{
Joachim Søreng Bjørge ${ }^{1,2}$, Svein Arne Bjørkheim ${ }^{3}$, Maria-Monika Metallinou ${ }^{4, *}$, \\ Torgrim Log 4 (D) and Øyvind Frette ${ }^{2}$ \\ 1 Q Rådgivning AS/PDS Protek, Øvregata 126, 5527 Haugesund, Norway; jsb@q-rad.no \\ 2 Department of Physics and Technology, University of Bergen, 5020 Bergen, Norway; \\ Oyvind.Frette@ift.uib.no \\ 3 Omega Areal AS, Kvassanesvegen 4, 5582 Ølensvåg, Norway; sveinarne@omega.no \\ 4 Western Norway University of Applied Sciences, Fire Disaster Research Group, 5528 Haugesund, Norway; \\ torgrim.log@hvl.no \\ * Correspondence: monika.metallinou@hvl.no; Tel.: +47-9882-5104
}

Received: 19 May 2019; Accepted: 17 June 2019; Published: 19 June 2019

\begin{abstract}
In the present work, the cooling efficiency of water droplets falling onto hot aluminum and stainless steel discs from heights of $12.5 \mathrm{~cm}, 25 \mathrm{~cm}, 50 \mathrm{~cm}$ and $100 \mathrm{~cm}$, corresponding to speeds of $1.5 \mathrm{~m} / \mathrm{s}, 2.2 \mathrm{~m} / \mathrm{s}, 3.1 \mathrm{~m} / \mathrm{s}$ and $4.4 \mathrm{~m} / \mathrm{s}$, respectively, were studied. The discs were aligned at $0^{\circ}$ (horizontal), $30^{\circ}$ and $60^{\circ}$ inclination. The water application rate was $0.022 \mathrm{~g} / \mathrm{s}$ and the droplet diameters studied were $2.5 \mathrm{~mm}, 3.2 \mathrm{~mm}$ and $3.7 \mathrm{~mm}$. Acetone solutions (300 ppm and $700 \mathrm{ppm}$ ) as well as a $\mathrm{NaCl}(35 \mathrm{~g} / \mathrm{kg})$ solution, emulating seawater, were tested to evaluate the influence of an active surfactant on the recorded cooling efficiency. The droplets with higher impact speed resulted in lower cooling efficiency, especially at disc temperatures above the Leidenfrost temperature, likely due to more vigorous droplets bouncing. Larger inclination did, as expected, result in lower cooling efficiency. At temperatures associated with nucleate boiling, the water droplets with $\mathrm{NaCl}$ conspicuously displayed higher cooling efficiency at about $110^{\circ} \mathrm{C}$. However, at temperatures between $120^{\circ} \mathrm{C}$ and the Leidenfrost temperature, acetone and $\mathrm{NaCl}$ additives did not significantly alter the cooling efficiency of the water droplets. Above the Leidenfrost temperature, a minor increase in cooling efficiency was observed for the acetone solutions. Overall, the additives only marginally changed the water droplet cooling efficiency. The standard industrial water application rate (i.e., $10 \mathrm{~L} / \mathrm{min} \cdot \mathrm{m}^{2}$ ) is shown to be insufficient compared to the heat fluxes expected in pool and jet fires (i.e., $250 \mathrm{~kW} / \mathrm{m}^{2}$ and $350 \mathrm{~kW} / \mathrm{m}^{2}$, respectively).
\end{abstract}

Keywords: hot metals; water droplet cooling efficiency; acetone; $\mathrm{NaCl}$

\section{Introduction}

From the start of the oil and gas industry (O\&G industry) on the Norwegian continental shelf, safety standards have been established and developed. These national standards and guidelines regulate several industrial safety aspects. This applies both to design and operation of facilities and installations on land and at sea. The industry must operate and maintain its facilities and equipment so that accidents, such as fires and explosions, are prevented.

During the last 3-4 decades, the international O\&G industry has experienced several major accidents [1,2]. Much work is therefore undertaken to limit the fire and explosion risks associated with processing highly combustible hydrocarbon products. However, severe fires in this industry still occur [2,3]. Equipment and piping is often constructed of different steel alloys, being especially 
vulnerable to impinging jet fires (i.e., the release of hydrocarbon gases under pressure resulting in well mixed high temperature flames of significant momentum). The weakening of exposed pressurized piping, equipment and load bearing constructions when heated may result in escalation of the fire scenario.

In the unfortunate scenario of an industrial fire, active fire protection is very important to prevent escalation of the incident. Among active fire protection measures, fire water systems prevail as outdoor fire protection, with the aim to cool fire exposed objects as well as to cool the flame zone to reduce heat exposure and prevent escalation. The NORSOK S-001 standard devotes a whole section to active fire protection [4]. For process areas, the design criteria are known to be standardized and general (e.g., $10 \mathrm{~L} / \mathrm{min} \cdot \mathrm{m}^{2}$ ). However, very few studies document cooling efficiency as a function of exposed metal temperature for representative water droplet sizes, which also includes all the relevant droplet cooling/evaporation regimes. The few studies found in the literature are generally devoted to horizontal objects [5].

Water droplets impinging onto hot surfaces display different boiling regimes, depending mainly on the surface temperature. The German theologist and physician Johann Gottlob Leidenfrost was the first scientist to study this phenomenon [6]. He noticed that when the temperature of a particular metal object exceeded a certain value, the water droplets were moving about at the hot metal surface with a very low evaporation rate (i.e., a very low cooling rate). Since then, it has become common to call the temperature for the onset of this phenomenon as the Leidenfrost temperature. Different parameters, like the metal itself (thermal properties) or surface roughness (depth of anomalies and pattern), as well as droplet size and deposition method used, exert influence on the observed Leidenfrost temperature. With increasing temperature, the cooling rates of hot metal objects impacted by water droplets go through a maximum in the nucleate boiling regime (i.e., where the critical heat flux is observed) and then decline rapidly in the transition boiling regime as vapor cushions develop below the droplets. At high temperatures, this process results in inefficient cooling, reaching a minimum value at the Leidenfrost temperature for the particular material. The Leidenfrost temperature is not fixed, as the droplet application mode also seems to exert a few $\mathrm{K}$ of influence. The importance of surface roughness appears ambiguous [7].

Bernardin and Mudawar [8] presented a review on Leidenfrost temperatures for water on heated materials. Liang and Mudawar [7] conducted a review concerning droplets impinging onto hot metals for all involved boiling regimes. Some researchers studied the behavior of different droplet parameters such as size, impingement velocity [9], wall material [10,11], temperature below the Leidenfrost point [12], influence of solid-liquid contact time [13], and evaporation of layers of aqueous salt solution [14]. Additives may also be used to reduce surface tension and thus enhance heat transfer [15,16]. Benedetto et al. [17] studied the phenomenon called combustion induced rapid phase transition (cRPT), and the effect different mixtures of $\mathrm{CH}_{4} / \mathrm{O}_{2} / \mathrm{N}_{2}$ have on this behavior. They found cRPT to be most conspicuous at $\mathrm{O}_{2}$ concentrations above $21 \mathrm{~mole} \%$. Bjørge et al. [5] presented a simple and straightforward method for obtaining the cooling efficiency of droplets impinging onto hot metal discs in the temperature range of $85^{\circ} \mathrm{C}$ to $410{ }^{\circ} \mathrm{C}$, covering all the boiling regimes experienced when water droplets are applied to hot metal objects.

The present study aims at analyzing: (a) The cooling efficiency of water droplets with various impingement speed and diameter falling on heated stainless steel discs with varied inclination, and (b) the effect of additives reducing surface tension on water droplet cooling efficiency. Experiments with acetone (additive, two different concentrations) were performed on aluminum discs for different impingement speeds at horizontal disc surface, as well as different surface inclinations for one selected impingement speed. The effect of adding $\mathrm{NaCl}$ at concentrations emulating seawater was also studied. The temperature range for all experiments was $85^{\circ} \mathrm{C}$ to $410{ }^{\circ} \mathrm{C}$, covering all water-droplet boiling regimes. The recorded droplet cooling efficiency for these different conditions is discussed. 


\section{Experimental Setup and Data Processing}

\subsection{Experiments on Stainless Steel Discs}

Discs (diameter: $50 \mathrm{~mm}$, thickness: $10 \mathrm{~mm}$, surface roughness Ra 3, pattern: concentric circles) were fabricated in Stainless steel AISI 316 (room temperature thermal conductivity approximately $15 \mathrm{~W} / \mathrm{m} \cdot \mathrm{K})$. The discs were suspended by four horizontal type $\mathrm{K}$ thermocouples (1.6 $\mathrm{mm}$ stainless steel mantel), as shown in Figure 1, thereby minimizing unnecessary heat losses. The thermocouples penetrated the disc radially at a $90^{\circ}$ angle, until $10 \mathrm{~mm}$ from the centre, and symmetrically as to the disc's thickness. The temperatures of the four thermocouples were recorded by a data logger (National Instruments NI cDAG-9184, Austin, TX, USA) at a frequency of $1 \mathrm{~s}^{-1}$. Their average temperature was recognized as the disc temperature.

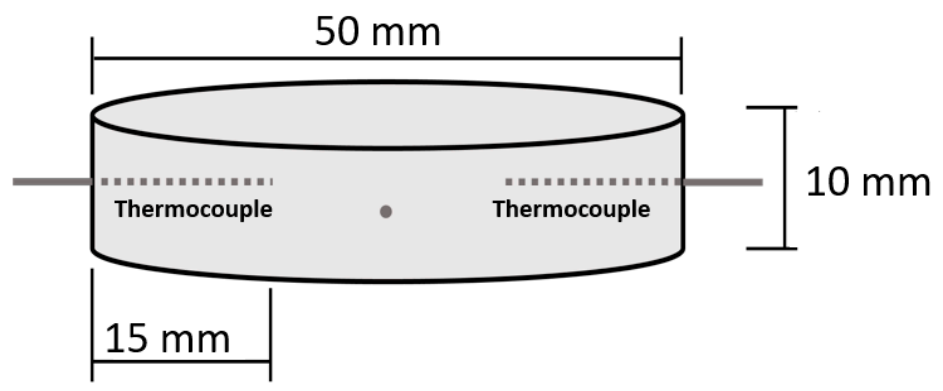

Figure 1. Sketch of metal disc with inserted thermocouples at $90^{\circ}$ horizontal separation [5].

The experimental setup and method is described in detail in [5] and the principal setup is shown in Figure 2.

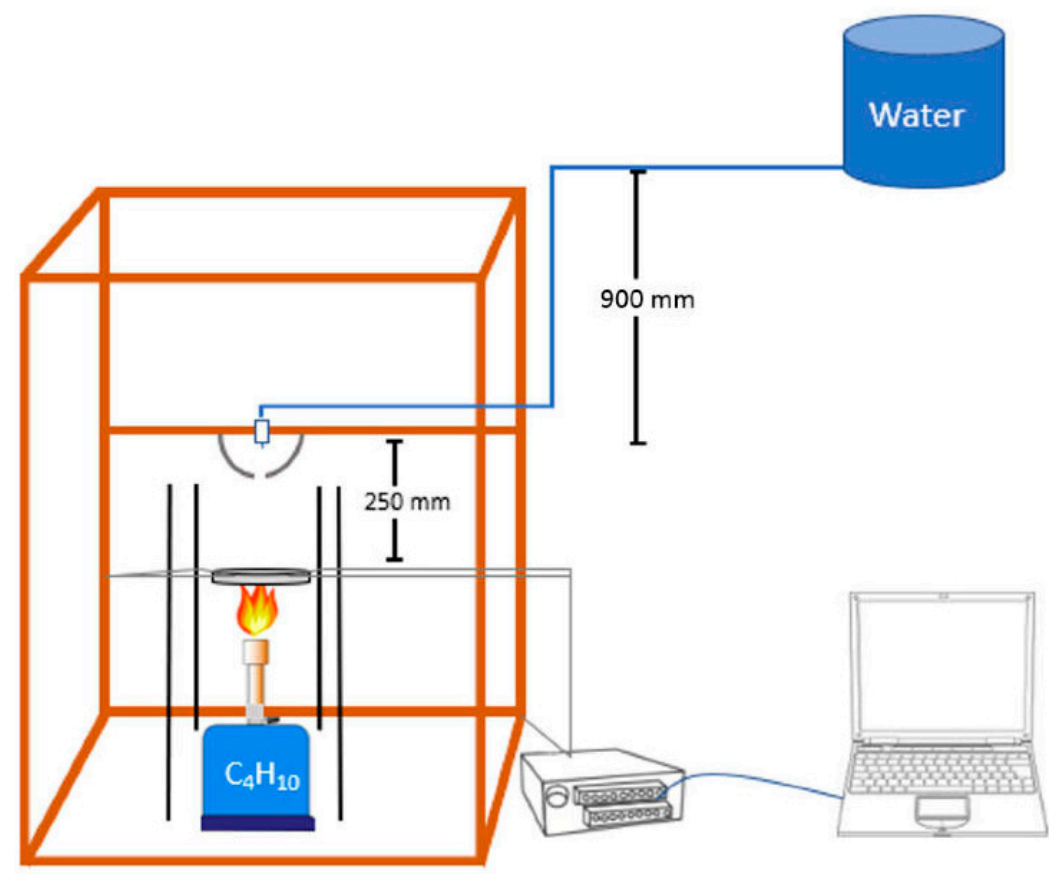

Figure 2. Sketch of the experimental setup. (The heater and the disc can be seen in the lower part of the air draft limiting frame).

The experimental procedure was as follows: The metal disc was first heated by a butane burner to about $430{ }^{\circ} \mathrm{C}$. Next, the burner was removed and the disc left to "air-cool" to $85^{\circ} \mathrm{C}$, thus establishing the baseline temperature decay for the dry-cooling (i.e., free cooling). During this period, the setup frame was covered by a fine mesh screen to prevent any air drafts influencing the measurements. 
Dry-cooling was also recorded after a series of droplet cooling experiments, with no more than 5 droplet (wet-cooling) experiments before a new dry-cooling temperature decay was recorded. This procedure ensured that any changes in ambient conditions in the laboratory would similarly affect both dry and wet-cooling recordings.

During the wet-cooling, droplets of distilled water with a flow rate of $0.022 \mathrm{~g} / \mathrm{s}$ (giving 2 to 3 droplets per second, depending on the droplet sizes) were supplied to the hot discs. The studied parameters were: droplet diameter $(2.5 \mathrm{~mm}, 3.2 \mathrm{~mm}$ and $3.7 \mathrm{~mm})$, impingement height $(25 \mathrm{~cm}, 50 \mathrm{~cm}$, $100 \mathrm{~cm}$, and surface inclination $\left(0^{\circ}\right.$ (horizontal), $30^{\circ}$ and $\left.60^{\circ}\right)$. Prior to the measurements, the discs were aligned using a leveler, and heated by the burner to about $430{ }^{\circ} \mathrm{C}$ (see Figure 2). The burner was then removed and the discs were cooled to $410{ }^{\circ} \mathrm{C}$, ensuring time for any internal temperature gradients to spatially equilibrate prior to water droplet application. The experiment as such (i.e., supply of water droplets) started when the disc had cooled beyond $410^{\circ} \mathrm{C}$. The measurement range used for the data analysis was from $400{ }^{\circ} \mathrm{C}$ to $85^{\circ} \mathrm{C}$, covering the principal droplet cooling regimes.

\subsection{Experiments on Aluminum Discs with $\mathrm{NaCl}$ and Acetone Additives}

To study droplet cooling efficiency with acetone and $\mathrm{NaCl}$ (salt) additives, aluminum (EN AW-6082) discs of $50 \mathrm{~mm}$ diameter and $10 \mathrm{~mm}$ thickness, surface roughness Ra 0.4 and thermal conductivities of about $170 \mathrm{~W} / \mathrm{m} \cdot \mathrm{K}$ were used. The choice of a material with much higher thermal conductivity than stainless steel was made to obtain results with less scattering [5]. The choice of a smooth surface (Ra 0.4) was made based on discrepancies in the literature as to the effect of surface roughness on cooling efficiency. Acetone solutions, as in the study by Bhatt et al. [16] (300 ppm (vol/vol) and $700 \mathrm{ppm}(\mathrm{vol} / \mathrm{vol})$ in distilled water) were used in the experiments, written as ppm throughout the article.

Droplets with a $2.5 \mathrm{~mm}$ diameter were released from heights of $0.125 \mathrm{~m}, 0.25 \mathrm{~m}$ and $0.50 \mathrm{~m}$, resulting in impingement speeds of $1.5 \mathrm{~m} / \mathrm{s}, 2.2 \mathrm{~m} / \mathrm{s}$ and $3.1 \mathrm{~m} / \mathrm{s}$, respectively [5]. This represents a variation in impact Weber number from 150 to 500 for the $300 \mathrm{ppm}$ acetone solution, 160 to 550 for the $700 \mathrm{ppm}$ acetone solution and 80 to 320 for the $\mathrm{NaCl}$ solution. The surface tension for the acetone solution supplied by [16] was used for the Weber number calculations. Because of the lowered surface tension when adding acetone, no larger droplet diameters were studied since any attempt to generate larger droplets with our injection needle technique [5] resulted in a continuous flow of water rather than droplets.

The aluminum surfaces were aligned at $0^{\circ}$ (horizontal), $30^{\circ}$ and $60^{\circ}$ for a $25 \mathrm{~cm}$ droplet fall height. At droplet fall heights of $12.5 \mathrm{~cm}$ and $50 \mathrm{~cm}$, only the horizontal configuration was studied. The $\mathrm{NaCl}$ was mixed into distilled water at room temperature to a concentration of $35 \mathrm{~g} \mathrm{NaCl} \mathrm{pr.} \mathrm{kg}$, emulating representative seawater which is often used for fire control in the $O \& G$ industry. The same test configuration and parameters as for the acetone tests were chosen for the droplet cooling experiments involving $\mathrm{NaCl}$.

Based on the differences in cooling rate with and without applying water droplets, disc mass and disc specific heat, the absolute cooling (in W) of the applied water droplets was determined. Droplet cooling was normalized by the water application rate and water evaporation heat to obtain the dimensionless cooling efficiency as a function of disc temperature, as briefly explained in Section 3.

The temperature range studied in the present work covered all droplet evaporation regimes. This included mass diffusion below $104{ }^{\circ} \mathrm{C}$ [18], nucleate boiling and increasing cooling efficiency at temperatures above $104{ }^{\circ} \mathrm{C}$ [19] until the critical temperature associated with maximum cooling efficiency followed by decreasing cooling efficiency to the Leidenfrost temperature, as well as film boiling at temperatures above the Leidenfrost temperature [6].

\section{Theory: Determining Cooling Efficiency}

Droplet impact point and principal convective air flows for upward facing disc surfaces in both horizontal and inclined disc positions are shown in Figure 3. 


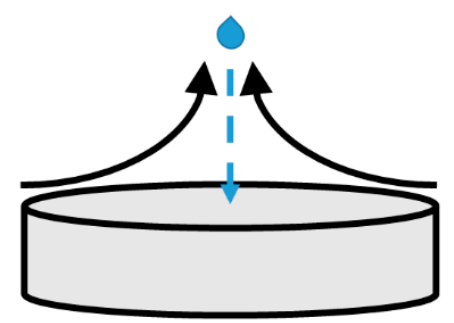

(a)

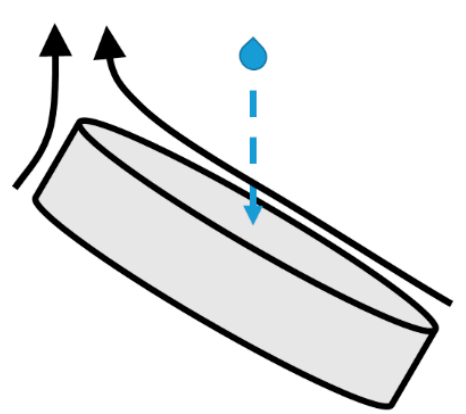

(b)

Figure 3. Sketch of the droplet impact point (blue lines) and convective air cooling flow for the upward facing disc surfaces (black lines) in both horizontal (a) and inclined surfaces (b).

Based on differences in cooling rates between dry- and wet-cooling, mass and specific heat of the disc for each orientation, the heat flow to the impinging water droplets can be calculated. Subtracting the respective temperature versus time derivatives for the given disc temperature gives the net water droplets cooling rate, $\left\{\frac{d T}{d t}(T)\right\}_{\text {Net }}(\mathrm{K} / \mathrm{s})$. Based on the mass, $m(\mathrm{~kg})$, and the specific heat, $C_{\mathrm{P}}(T)(\mathrm{J} / \mathrm{kg} \mathrm{K})$, of the disc as a function of temperature, the water droplet cooling heat flow is given by:

$$
\dot{Q}_{\text {Drops }}(\mathrm{T})=m_{\text {Disc }} \cdot C_{\mathrm{P}}(T) \cdot\left\{\frac{d T}{d t}(T)\right\}_{\text {Net }}(\mathrm{W}),
$$

In the present work, the specific heat data for stainless steel and aluminum given by [5] were used in Equation (1). Ignoring the enthalpy needed to heat the water to $100{ }^{\circ} \mathrm{C}$ and heat the steam above $100{ }^{\circ} \mathrm{C}$, the heat required to evaporate droplets at a rate, $\dot{m}_{\text {Drops }}(\mathrm{kg} / \mathrm{s})$, is given by:

$$
\dot{Q}_{\text {Max }}=\dot{m}_{\text {Drops }} \cdot \Delta H_{\text {vap }}(\mathrm{W}) \text {. }
$$

Representative recordings of temperature versus time for dry-cooling and wet-cooling (by applying water droplets) are shown in Figure 4. The respective heat losses are shown in Figure 5. It can be seen from Figures 4 and 5 that dry-cooling was faster for the inclined orientation than for the horizontal orientation. Prior to, and after a measurement series, the free-cooling temperature versus time history was therefore always obtained. It should also be noted that the discs loose heat by thermal radiation, which was assumed independent on inclination.

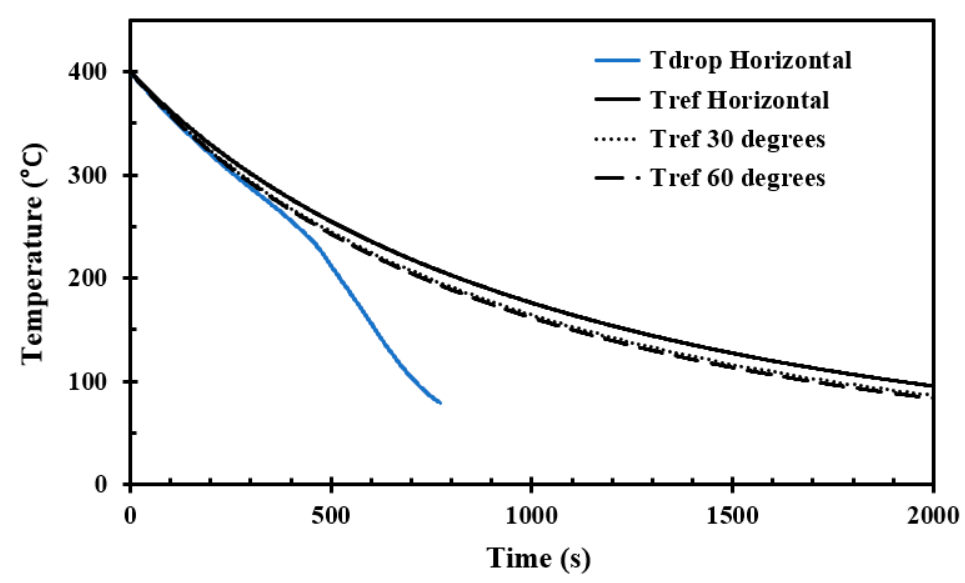

Figure 4. Temperature versus time for a representative stainless steel disc with $2.4 \mathrm{~mm}$ diameter droplets and $25 \mathrm{~cm}$ impingement height, including reference (dry-cooling) recordings for horizontal, $30^{\circ}$ and $60^{\circ}$. 


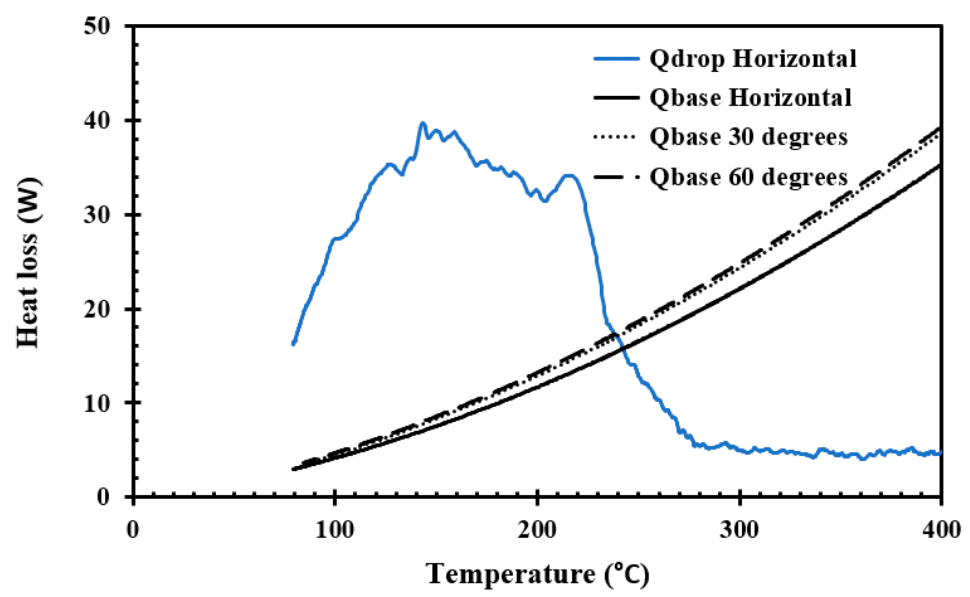

Figure 5. Heat loss to the water droplets in a representative test for droplets impinging a horizontal stainless steel disc, the corresponding dry-cooling (reference) heat loss for the horizontal disc and similar dry-cooling heat losses for $30^{\circ}$ and $60^{\circ}$ inclined discs.

The relative droplet cooling efficiency can then be calculated by:

$$
\xi=\dot{Q}_{\text {Drops }}(\mathrm{T}) / \dot{Q}_{\text {Max }}
$$

\section{Cooling Efficiency Results}

\subsection{Pure Water Droplets on Hot Stainless Steel Discs}

4.1.1. Effect of Inclination on Cooling Efficiency at $25 \mathrm{~cm}$ Impingement Height, for Various Droplet Diameters

The results obtained for the selected droplet diameters at $0^{\circ}$ (horizontal) $30^{\circ}$ and $60^{\circ}$ orientation are presented in Figures 6-8, respectively. Each curve represents the average of 5 measurement series with identical conditions.

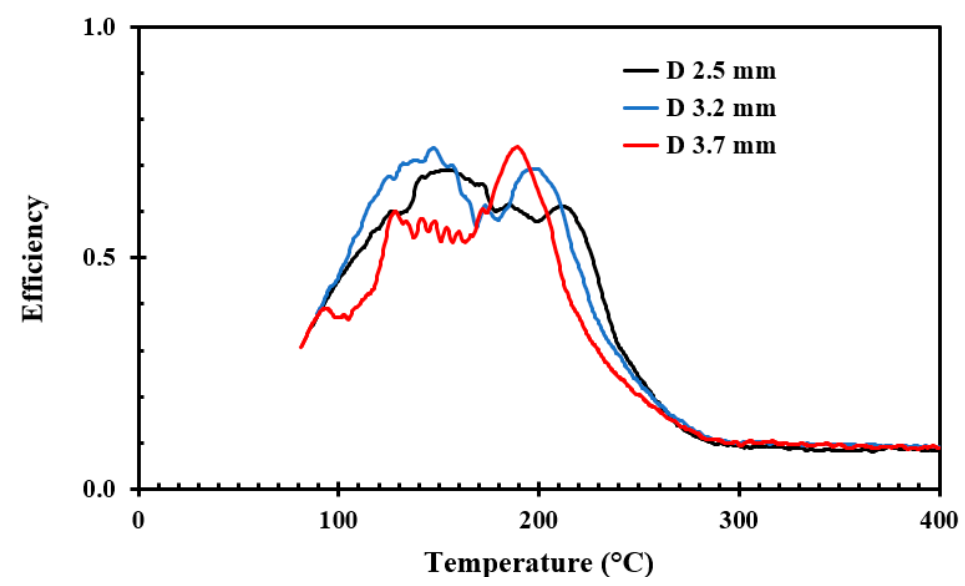

Figure 6. Cooling efficiency for pure water droplets with $25 \mathrm{~cm}$ impingement height for horizontal orientation and various droplet diameters. Droplet speed $2.2 \mathrm{~m} / \mathrm{s}$.

The results indicate highest cooling efficiency for the horizontal discs. This may be due to droplets remaining on the surface for a longer period. For the most inclined surface, $60^{\circ}$, the effect of the droplet size is limited. However, the results indicate that the smallest droplets display the lowest cooling efficiency. Similar results were also obtained for impingement height $50 \mathrm{~cm}$ and $100 \mathrm{~cm}$ (results not included). 


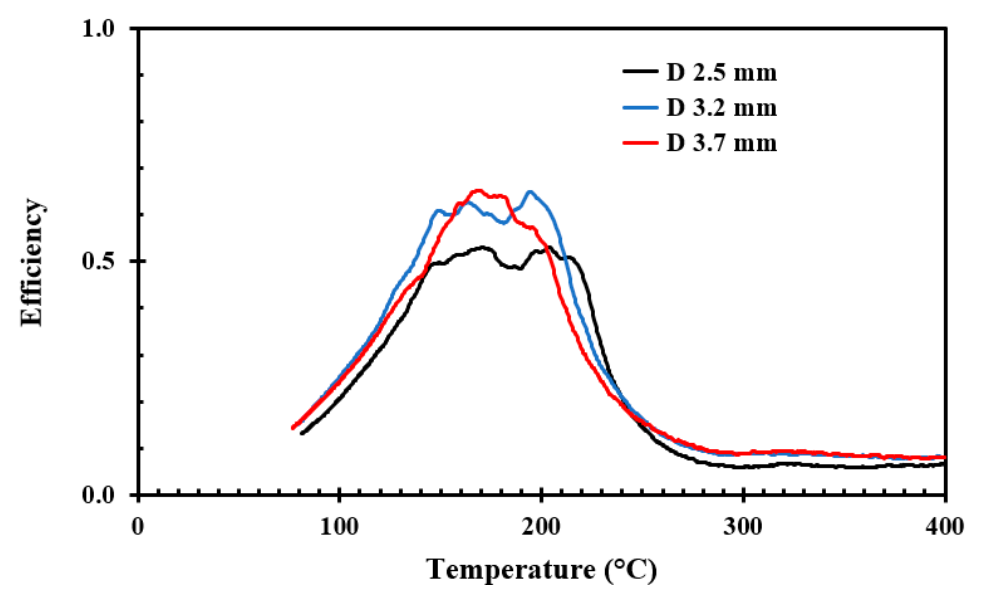

Figure 7. Cooling efficiency for pure water droplets with $25 \mathrm{~cm}$ impingement height for $30^{\circ}$ inclination and various droplet diameters. Droplet speed $2.2 \mathrm{~m} / \mathrm{s}$.

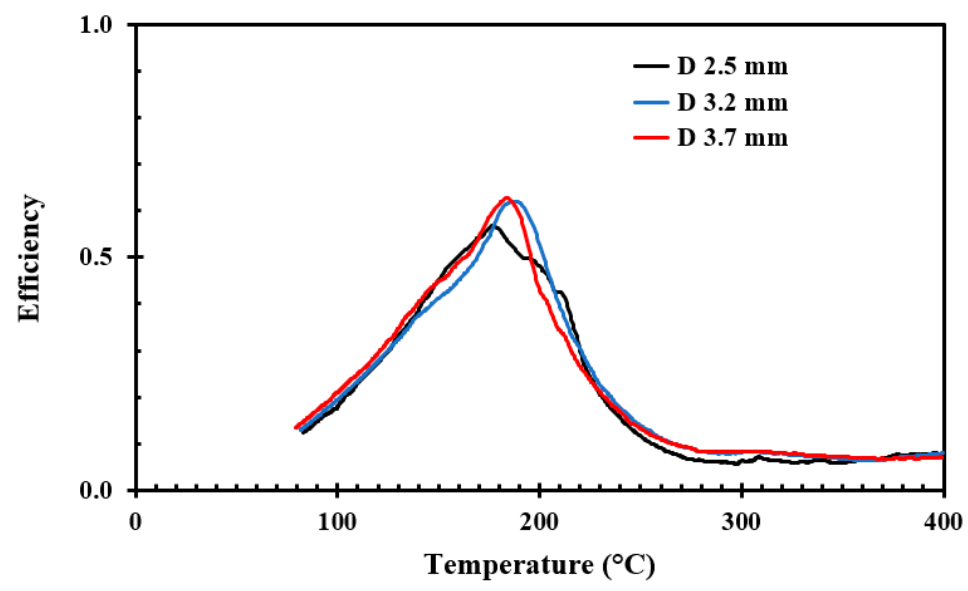

Figure 8. Cooling efficiency for pure water droplets with $25 \mathrm{~cm}$ impingement height for $60^{\circ}$ inclination and various droplet diameters. Droplet speed $2.2 \mathrm{~m} / \mathrm{s}$.

4.1.2. Effect of Inclination on Cooling Efficiency for Droplet Diameter $2.5 \mathrm{~mm}$ for Various Impact Speeds

The results obtained for $25 \mathrm{~cm}, 50 \mathrm{~cm}$ and $100 \mathrm{~cm}$ impingement heights for $0^{\circ}$ (horizontal), 30 and $60^{\circ}$ inclination are presented in Figures 9-11, respectively.

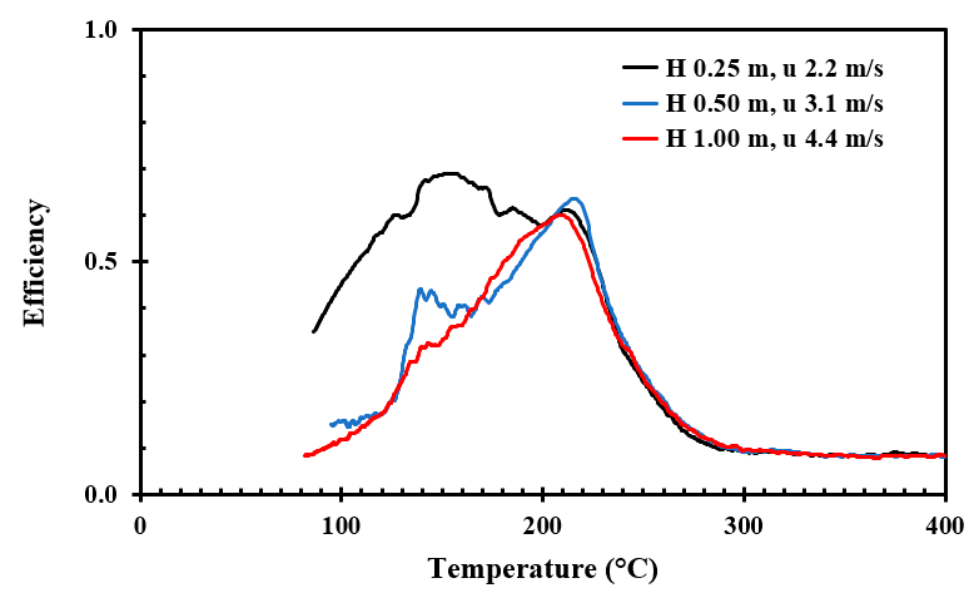

Figure 9. Cooling efficiency for pure water droplets at horizontal disc orientation, droplet diameter $2.5 \mathrm{~mm}$. Impingement heights and speeds are given in the figure label. 


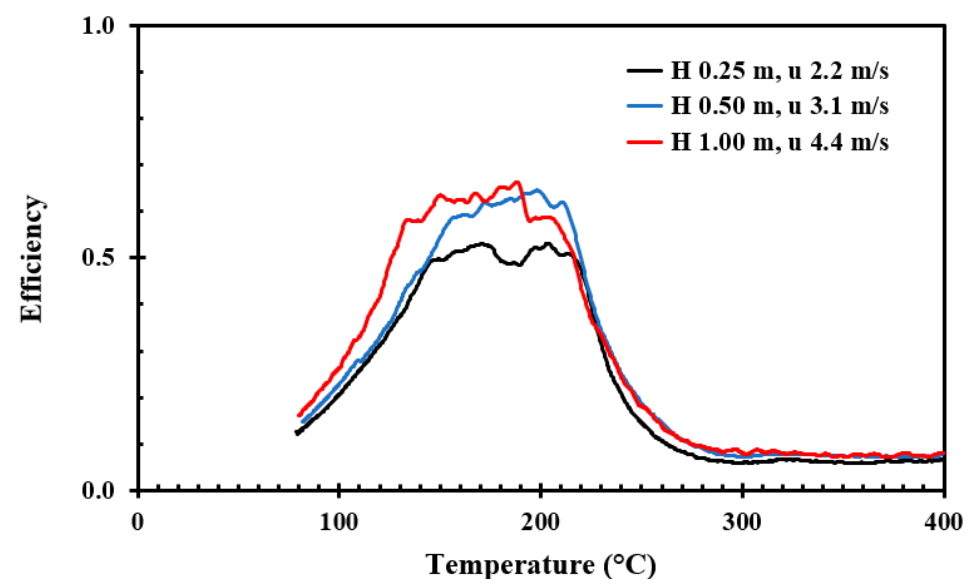

Figure 10. Cooling efficiency for pure water droplets at $30^{\circ}$ disc inclination, droplet diameter $2.5 \mathrm{~mm}$. Impingement heights and speeds are given in the figure label.

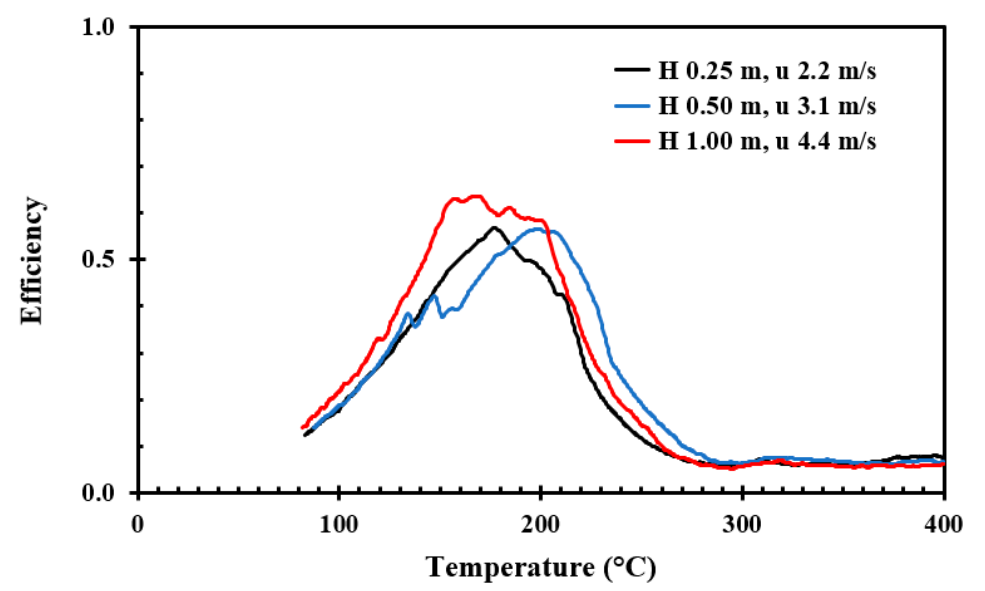

Figure 11. Cooling efficiency for pure water droplets at $60^{\circ}$ disc inclination, droplet diameter $2.5 \mathrm{~mm}$. Impingement heights and speeds are given in the figure label.

For impingement height $25 \mathrm{~cm}$, the results indicate that horizontal orientation gave the highest cooling efficiency at temperatures of about $150{ }^{\circ} \mathrm{C}$. This may be due to droplets remaining on the surface for a longer period. For inclined surfaces, increasing impingement height seems to increase cooling efficiency, though the cooling efficiency curves cross for parts of the investigated temperature range. Similar results were obtained for droplet diameter $3.2 \mathrm{~mm}$ and $3.7 \mathrm{~mm}$ (results not included).

The effect of inclination when both droplet diameter and impingement height were fixed is summarized in Figure 12. The three curves are previously presented in Figure 9 (black curve in Figure 12), Figure 10 (blue curve in Figure 12) and Figure 11 (red curve in Figure 12).

\subsection{Cooling Efficiency of Water Droplets with Additives}

\subsubsection{Cooling Efficiency for Horizontal Orientation and Varying Impact Speeds}

The results obtained for the water droplets with acetone and $\mathrm{NaCl}$ additives compared to the results for pure water droplets are shown in Figures 13 and 14 for 12.5 and $25 \mathrm{~cm}$ impingement height, respectively.

As presented in Figures 13 and 14, the 700 ppm acetone in water gave the highest cooling efficiency in the transition boiling regime and highest cooling efficiency at boiling crisis; the cooling efficiency increased from $80 \%$ to $90 \%$ at boiling crisis. For the $\mathrm{NaCl}$ additive, it is interesting to notice that the cooling efficiency was conspicuously increased at about $110^{\circ} \mathrm{C}$ compared to the other experiments. The 
nucleate boiling regime is clearly in a narrower temperature range, and the Leidenfrost temperature is slightly increased.

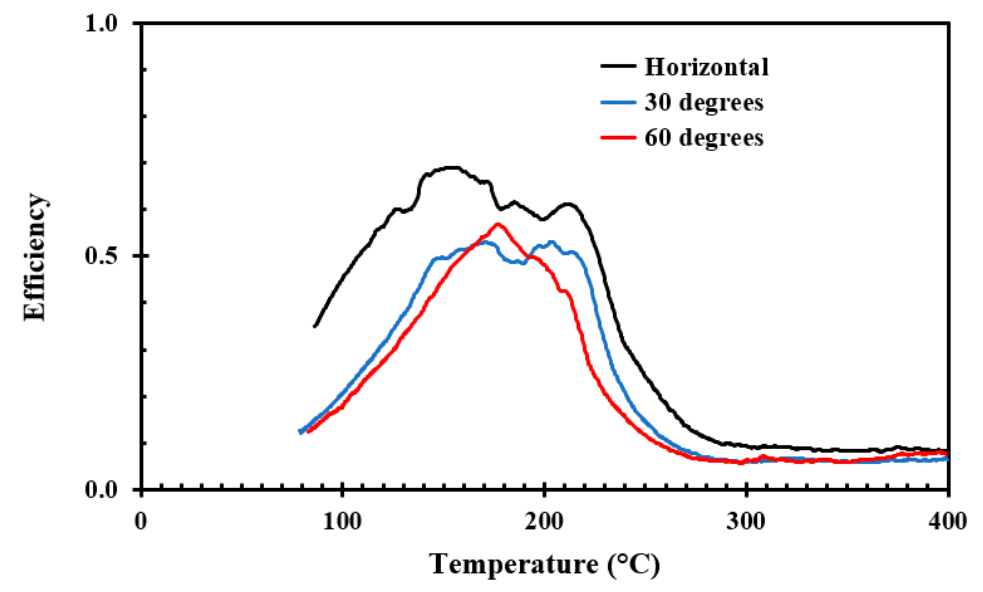

Figure 12. Cooling efficiency for pure water droplets with diameter $2.5 \mathrm{~mm}$, various orientations at impingement height $25 \mathrm{~cm}$ and speed $2.2 \mathrm{~m} / \mathrm{s}$.

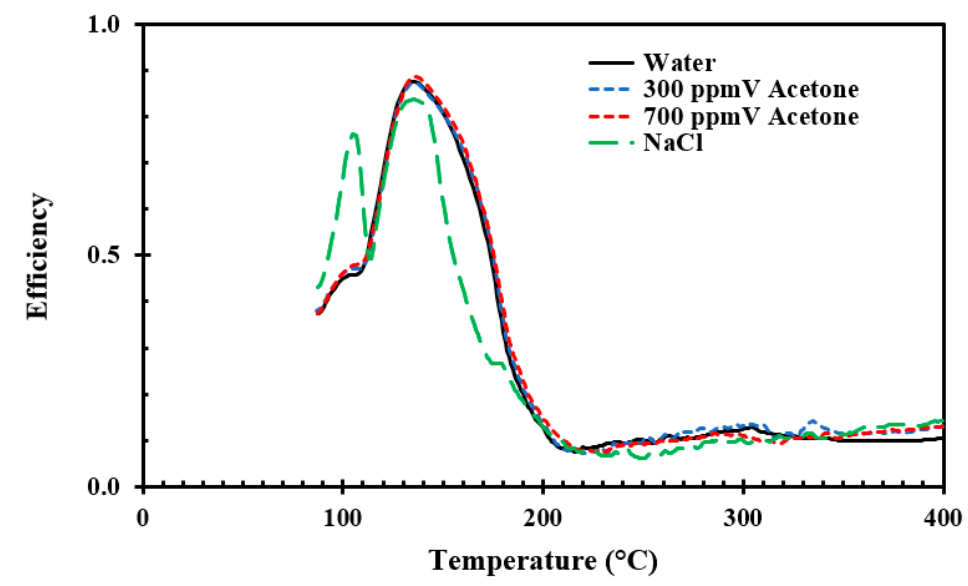

Figure 13. Cooling efficiency for water droplets with and without additives for droplet diameter $2.5 \mathrm{~mm}$, horizontal orientation at impingement height $12.5 \mathrm{~cm}$ (speed $1.5 \mathrm{~m} / \mathrm{s})$.

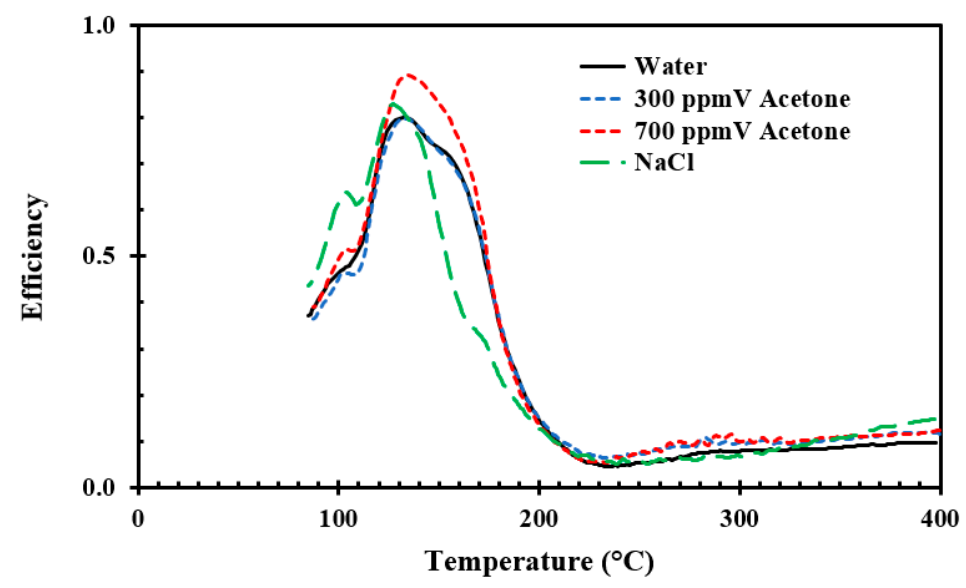

Figure 14. Cooling efficiency for water droplets with and without additives for droplet diameter $2.5 \mathrm{~mm}$, horizontal orientation at impingement height $25 \mathrm{~cm}$ (speed $2.2 \mathrm{~m} / \mathrm{s}$ ).

The addition of $300 \mathrm{ppm}$ acetone had a limited effect compared to pure water. This contradicts to the findings of Bhatt et al. [16]. However, they observed foam-formation from the given mixture 
applied to their hot disc in form of a spray. The foam was believed to develop due to the combination of low surface tension of the mixture combined with the sprays' high mass flux (described to be in the range of $45.6-125.4 \mathrm{~kg} / \mathrm{m}^{2} \cdot \mathrm{s}$ ) which is considerably larger than that used in our experiments, where no foam was observed. However, for temperatures above the Leidenfrost point (Figure 13), our results confirm the results of Bhatt et al. [16], where the 300 ppm acetone solution achieved slightly higher cooling efficiency than $700 \mathrm{ppm}$ solution for the $12.5 \mathrm{~cm}$ impingement height.

\subsubsection{Effect of Inclination on Cooling Efficiency}

The results obtained for various disc orientations are presented in Figures 15-17 for 300 ppm and $700 \mathrm{ppm}$ acetone solutions and $35 \mathrm{~g} / \mathrm{kg} \mathrm{NaCl}$ solution, respectively.

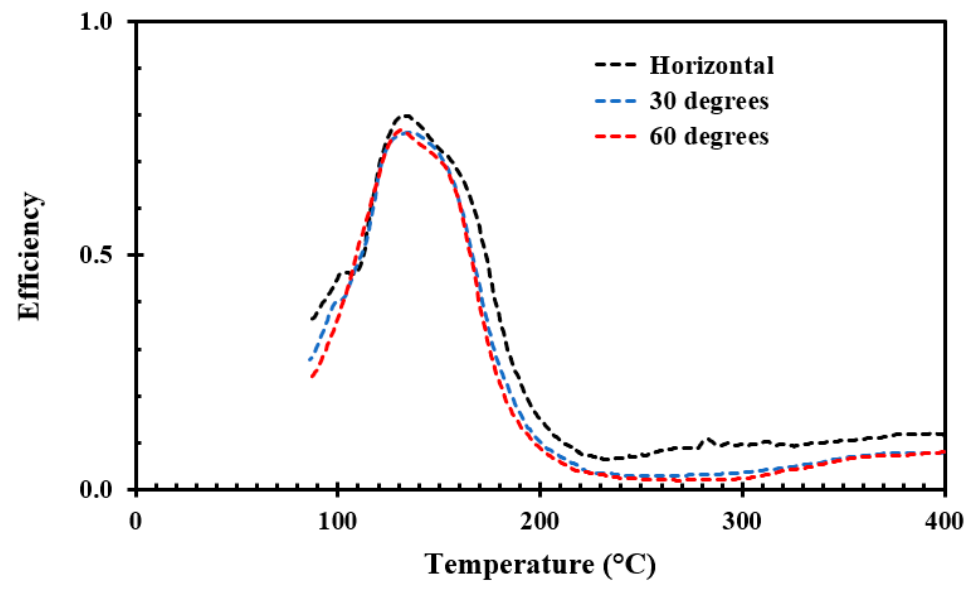

Figure 15. Cooling efficiency for 300 ppm acetone water solution for droplet diameter $2.5 \mathrm{~mm}$, and various orientations at impingement height $25 \mathrm{~cm}$ (speed $2.2 \mathrm{~m} / \mathrm{s}$ ).

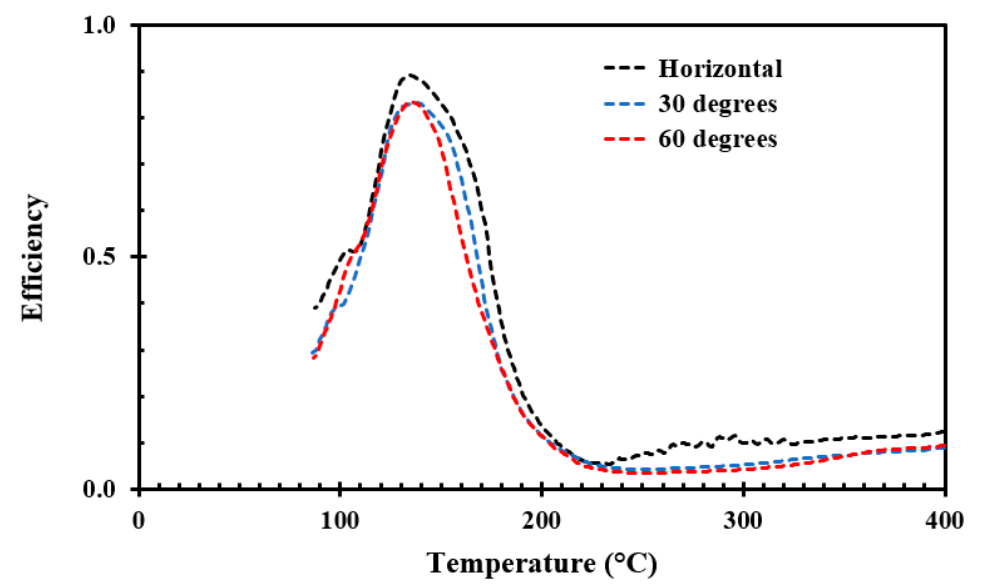

Figure 16. Cooling efficiency for $700 \mathrm{ppm}$ acetone water solution for droplet diameter $2.5 \mathrm{~mm}$, and various orientations at impingement height $25 \mathrm{~cm}$ (speed $2.2 \mathrm{~m} / \mathrm{s})$. 


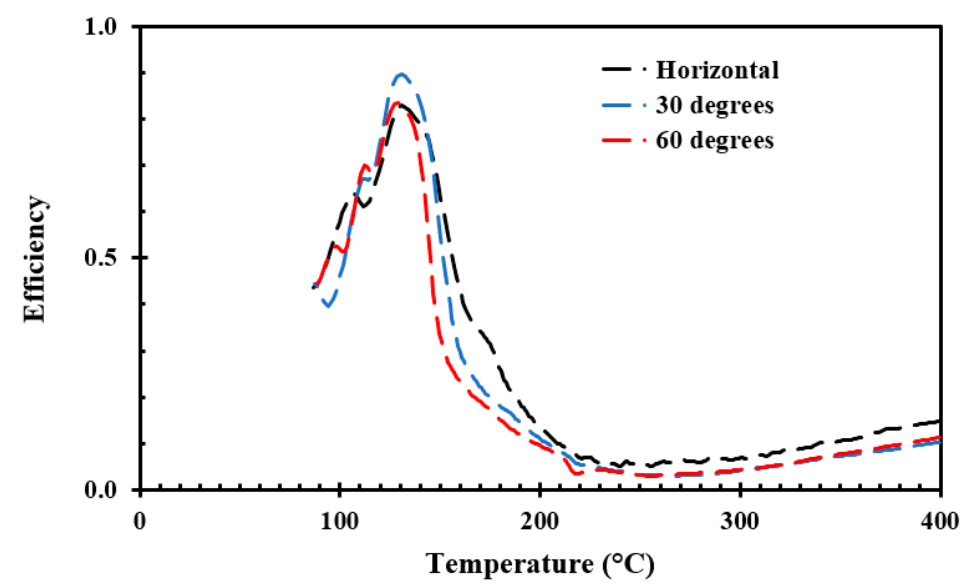

Figure 17. Cooling efficiency for $35 \mathrm{~g} / \mathrm{kg} \mathrm{NaCl}$ water solution for droplet diameter $2.5 \mathrm{~mm}$, and various orientations at impingement height $25 \mathrm{~cm}$ (speed $2.2 \mathrm{~m} / \mathrm{s}$ ).

\subsubsection{Effect of Impact Speed on Cooling Efficiency}

The results obtained for variation in impinging heights are presented in Figures $18-20$ for $300 \mathrm{ppm}$ and $700 \mathrm{ppm}$ acetone solutions and $35 \mathrm{~g} / \mathrm{kg} \mathrm{NaCl}$ solution, respectively.

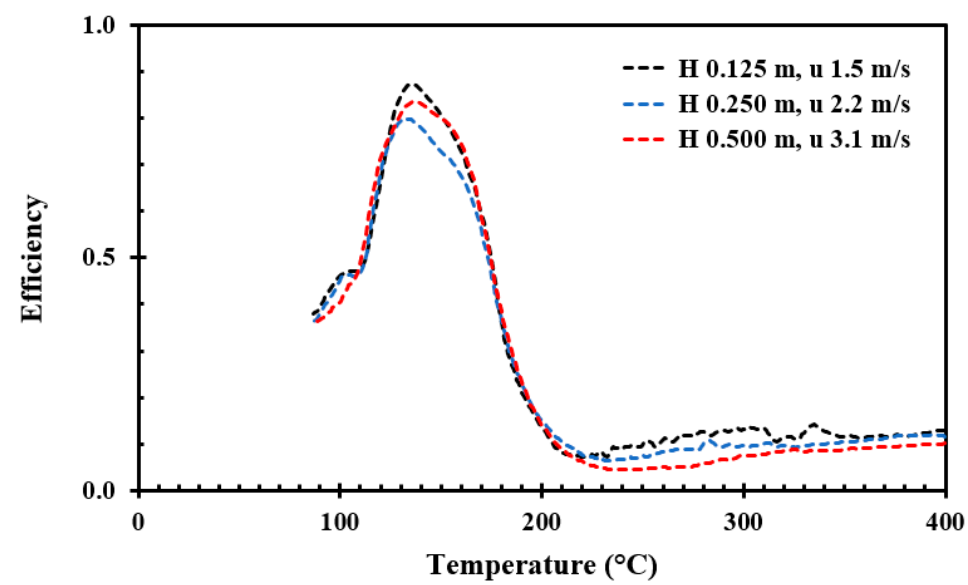

Figure 18. Cooling efficiency for $300 \mathrm{ppm}$ acetone solution for droplet diameter $2.5 \mathrm{~mm}$, horizontal orientation. Impingement heights and speeds are given in the figure label.

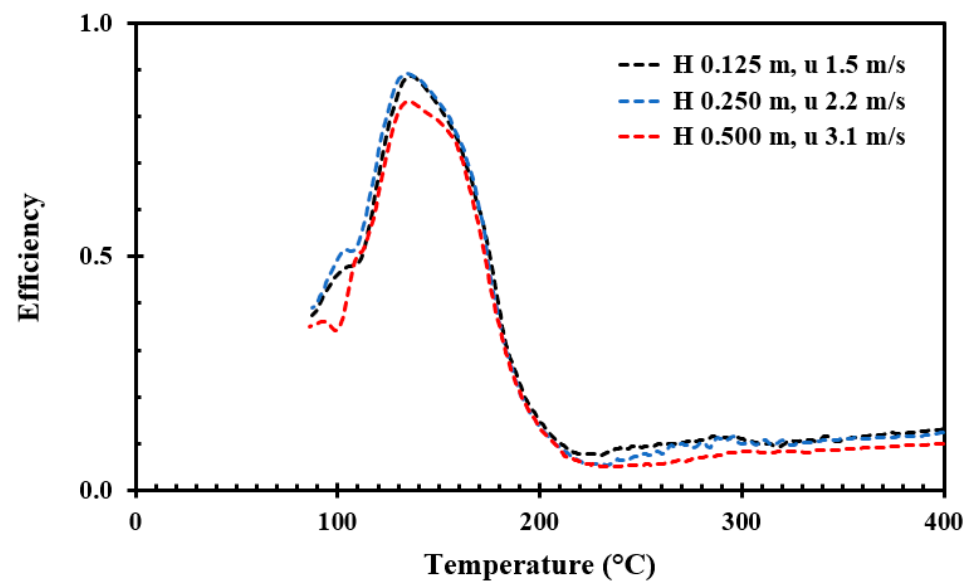

Figure 19. Cooling efficiency for $700 \mathrm{ppm}$ acetone solution for droplet diameter $2.5 \mathrm{~mm}$, horizontal orientation. Impingement heights and speeds are given in the figure label. 


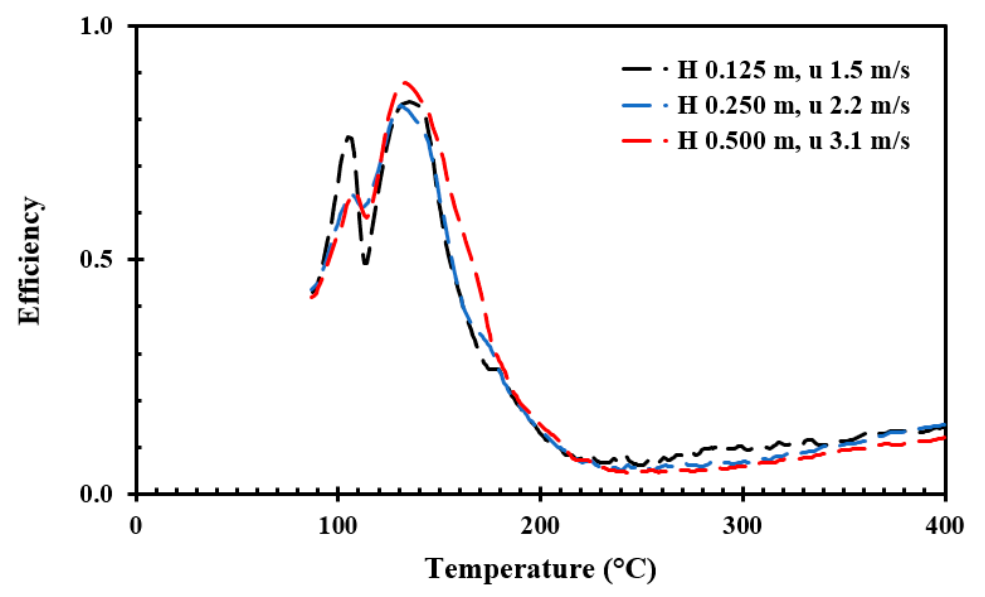

Figure 20. Cooling efficiency for $35 \mathrm{~g} / \mathrm{kg} \mathrm{NaCl}$ solution for droplet diameter $2.5 \mathrm{~mm}$, horizontal orientation. Impingement heights and speeds are given in the figure label.

The standard deviation of the efficiency recorded for horizontal orientation and $25 \mathrm{~cm}$ impingement height as a function of temperature is presented in Figure 21.

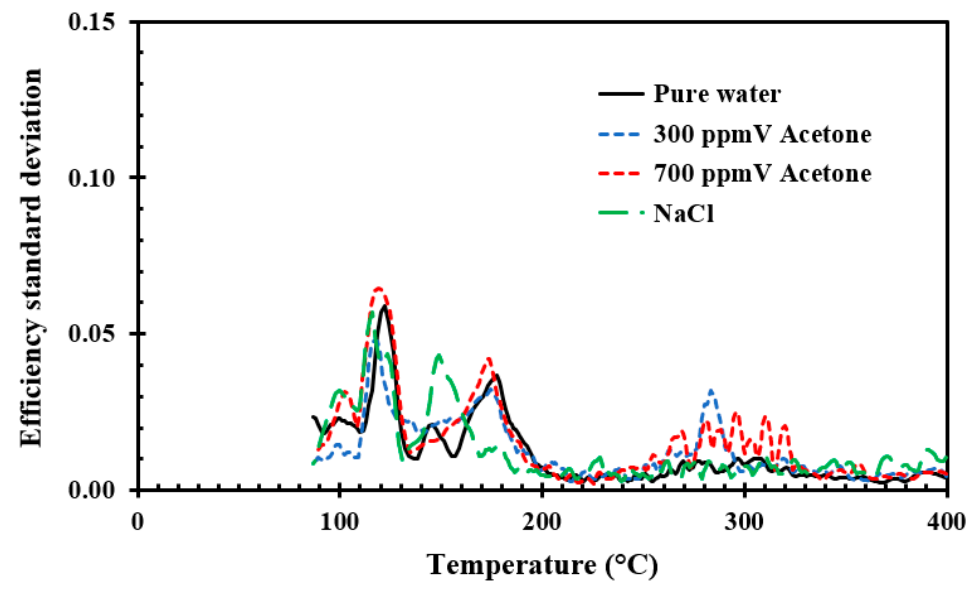

Figure 21. Comparison of cooling efficiency standard deviation for horizontal orientation at $25 \mathrm{~cm}$ impingement height and speed $2.2 \mathrm{~m} / \mathrm{s}$.

To evaluate whether the efficiency recorded for the aluminum discs with different mixtures of surfactants were significantly different, as well as different compared to pure water, a Student's $t$-test was introduced requiring an alpha $<0.05$. The difference in cooling efficiency as presented in Figures 13-20 was, through the complete temperature range, i.e., $85^{\circ} \mathrm{C}$ to $400^{\circ} \mathrm{C}$, for all configurations not statistically valid, with only two exceptions. The exceptions were the comparison between $12.5 \mathrm{~cm}$ and $50 \mathrm{~cm}$ impingement height for the $700 \mathrm{ppm}$ acetone solutions and the conspicuous peak in cooling efficiency for the $\mathrm{NaCl}$ solution at $110^{\circ} \mathrm{C}$.

\subsection{Error Analysis}

Only minor variations in the droplet application rate and droplet diameter were observed. The standard deviation for the water application rate was within $3 \%$ and for the droplet diameter, it was within $\pm 1 \%$. The $25 \mathrm{~cm}$ impingement height was measured to within $1 \mathrm{~mm}$, that is, giving less than $1 \%$ error in the calculated droplet speed. Given the rather large standard deviations for the observed water droplet efficiency, the droplet diameter, application rate and droplet speed can be considered sufficiently constant for comparing the results from the different measurement series. 
Before each measurement series, the discs were aligned horizontally $\left(0^{\circ}\right), 30^{\circ}$ and $60^{\circ}$ to within $0.5^{\circ}$. Some slight misalignment during the heating and cooling cycles cannot be completely excluded, and this may to some extent influence the results. However, misalignment larger than $1^{\circ}$ was not observed after the completion of each measurement series. It is therefore reasonable to believe that differences recorded in the water droplet cooling efficiencies were caused by the parameters altered on purpose.

\section{Discussion}

When assessing different parameters, such as surface roughness, the expected steam layer thickness is an essential parameter. Using computational methods, Chatzikyriakou et al. [20] showed that the vapor layer exhibits oscillations for sessile water droplets, eventually settling to a thickness in the range of $20-40 \mu \mathrm{m}$. This result is also supported by the theoretical value obtained by Wachters et al. [21] for similar droplet conditions $(28.9 \mu \mathrm{m})$. Some contradictions were presented in $[7,22]$ regarding the surface roughness influence on the heat transfer for the transition boiling and film boiling regime. Whereas some researchers describe increasing surface roughness to increase the heat transfer, others claim the opposite. It is believed that this contradiction can be related to the fact that some heat transfer dependences are valid in certain surface roughness ranges. There are also different ways of producing a given surface roughness; for example, the surface pattern could differ significantly, while still giving the same Ra value. This was the main reason for choosing Ra 0.4 (smooth surface) as a primary surface roughness for the experiments with acetone surfactant additives.

In the present work, there was no flame present during the water droplet cooling of the hot discs. Additionally, when applying water droplets, the discs were always the hottest object, hotter than the generated steam from the evaporating droplets. No condensation would therefore occur on the disc. The presented method could therefore not reveal phenomena such as cRPT [17].

For the horizontally aligned stainless steel discs, the smallest droplets were observed to give a higher cooling efficiency over a wider temperature range. This is probably due to the larger relative contact surface area to the volume of the smaller droplets. The largest droplets demonstrated higher peak efficiency (i.e., higher cooling efficiency at boiling crisis) which was recorded to be in the range of $64-75 \%$ for the different configurations. The droplet cooling efficiency increased slightly with increasing impact velocity for $30^{\circ}$ and $60^{\circ}$ orientation. This is believed to be due to a rise in pressure inside the droplet and slowdown of the steam layer. For horizontal orientation, a higher cooling efficiency over a wider temperature range was observed for the lowest impact velocity. A reason for this could be the two identified boiling regimes/mechanisms of droplet bouncing based on Weber-number (We), as described by Biance et al. [23]. In the first boiling regime, which represents droplet impingement at high We, drop impact inertia is significantly greater than surface tension. This renders the rebound less elastic. Due to droplet break up, the droplet more easily bounces off the hot metal disc.

For the horizontal configuration, droplet bouncing was more prominent for the largest droplets while the smaller droplets (lower Weber number) tended to attach better to the surface. The droplet cooling efficiency was shown to decrease with increased inclination for the lowest impact velocity (2.2 $\mathrm{m} / \mathrm{s}$ ). For higher droplet velocities, an increase in cooling efficiency for $30^{\circ}$ inclination was observed. In line with the results of other researchers [8], a cooling efficiency maximum was observed at $130^{\circ} \mathrm{C}$ to $210{ }^{\circ} \mathrm{C}$. In the film boiling regime, at temperatures above the Leidenfrost temperature $\left(290-300{ }^{\circ} \mathrm{C}\right)$, the cooling efficiency was reduced to about $10 \%$. This result was also in agreement with previous research [8], with the added value in the present study being a concrete value for the cooling efficiency. For industrial fire water applications, a standard water supply rate of $10 \mathrm{~L} / \mathrm{min} \cdot \mathrm{m}^{2}$ gives a cooling capacity of $43 \mathrm{~kW} / \mathrm{m}^{2}$ at $10 \%$ cooling efficiency. This cooling heat flux is significantly lower than expected heat fluxes associated with pool and jet fires $\left(250 \mathrm{~kW} / \mathrm{m}^{2}\right.$ and $350 \mathrm{~kW} / \mathrm{m}^{2}$, respectively) [4].

For the aluminum discs, the water droplet cooling efficiency was not significantly altered by adding acetone surfactant. The Leidenfrost point was only marginally changed for the horizontal orientation and the cooling efficiency increased approximately $2 \%$ at higher temperatures. However, 
the cooling efficiency at boiling crisis increased by $12 \%$ compared to pure water when using $700 \mathrm{ppm}$ acetone and $25 \mathrm{~cm}$ impingement height. A similar trend was not observed in the other configurations. The droplet cooling efficiency increased slightly with a decrease in impact velocity. An increase in droplet velocity gave no conclusive indication at temperatures below the Leidenfrost temperature, however a low velocity gave a higher cooling efficiency in the film boiling regime. A reason for this may be as already mentioned and is supported by the study of Biance et al. [23]. The observed Leidenfrost temperature was not significantly altered. Bhatt et al. [16] reported that the droplet speed had to be $13.5-20 \mathrm{~m} / \mathrm{s}$ for droplets less than $0.45 \mathrm{~mm}$ to significantly increase the Leidenfrost temperature when $300 \mathrm{ppm}$ acetone surfactant was added.

A cooling efficiency maximum at $120-140{ }^{\circ} \mathrm{C}$ was observed for all aluminum disc tests. This temperature range is significant smaller than observed for the stainless steel tests. This is likely due to an order of magnitude higher thermal conductivity for aluminum versus stainless steel (i.e., $170 \mathrm{~W} / \mathrm{m} \cdot \mathrm{K}$ versus $15 \mathrm{~W} / \mathrm{m} \cdot \mathrm{K})$. In the film boiling regime, at temperatures above the Leidenfrost temperature (230-240 $\left.{ }^{\circ} \mathrm{C}\right)$, the cooling efficiency was in the range of $4-10 \%$ dependent on the aluminum disc orientation, where increased inclination gave a decrease in cooling efficiency. This is most likely due to impinging droplets more easily bouncing off after their first collision.

In the experiments with emulated seawater $(35 \mathrm{~g} \mathrm{NaCl} / \mathrm{kg})$, two distinct peaks were observed; the first at approximately $110^{\circ} \mathrm{C}$ and the second at $130^{\circ} \mathrm{C}$ (i.e., the temperature of critical heat flux for the aluminum discs). For the first temperature peak, salt was observed along the edge of the droplet contact area. The salt layer, which started to form on the metal surface, is believed to increase the evaporation rate in the triple-phase (liquid-gas-solid). A similar observation was made by Cui et al. [24].

The nucleate boiling regime was observed to be narrower for the $\mathrm{NaCl}$ solution while the transition boiling regime was prolonged and the Leidenfrost temperature was significantly increased (i.e., about 20-30 K) compared to pure water. This is in agreement with the observations of other researchers [25].

In fire water piping, there may be alien objects, like gravel, remains of mussels, etc. Such objects may restrict the flow of the system, in the worst cases render the system inoperable. Fire water systems therefore need to be tested regularly for confirming the system functionality. Using seawater for fire water raises concerns due to corrosion under insulation as well as corrosion attacks on cabling and instrumentation. The limited differences in cooling efficiency between pure water and $35 \mathrm{~g} / \mathrm{kg} \mathrm{NaCl}$ solution observed in the present study therefore do not support that seawater should be the preferred fire water supply.

It should be mentioned that the conspicuous nucleate boiling regime peak in $\mathrm{NaCl}$ solution cooling efficiency may be a result of the present study test method. If seawater was applied to the hot surface while the surface temperature was increasing rather than decreasing, the results could be altered in favor of salt water given that more salt may be deposited on the surface, increasing the water droplet surface contact. To test this was not possible with the current setup, and was therefore outside the scope of the present study.

For temperatures above the Leidenfrost temperature, the observed cooling efficiency slightly increased with increasing temperature up to $400{ }^{\circ} \mathrm{C}$. This is most likely caused by the increasing temperature difference between the evaporating levitated droplets and the disc surface. The increase was, however, larger for the aluminum discs than for the stainless steel discs. An interpretation of this finding would require further studies.

During the droplet cooling, temperature gradients will be set up in the disc, especially when using stainless steel as the disc material. However, to analyze this was outside the scope of the present study. For future studies, it would be interesting to do backwards numerical analysis based on the recoded heat loss rates to reveal the magnitude of the internal temperature gradients.

\section{Conclusions}

The reported low film boiling regime cooling efficiency for pure water, as well as for $35 \mathrm{~g} / \mathrm{kg} \mathrm{NaCl}$ solution, $300 \mathrm{ppm}$ and $700 \mathrm{ppm}$ acetone solutions, demonstrates the importance of activating fire water 
deluge or monitors early in case of an industrial fire. Else, it may be very difficult to cool exposed pipes, equipment and structural members. Late activation of fire water will, due to the low cooling efficiency, have limited effect for temperatures at and above the Leidenfrost temperatures. Overall, the additives only marginally improved the water droplet cooling efficiency. It may therefore be concluded that the standard industrial water application rate (i.e., $10 \mathrm{~L} / \mathrm{min} \cdot \mathrm{m}^{2}$ ) is insufficient compared to the heat fluxes expected in industrial pool and jet fires.

Author Contributions: T.L. conceived the concept. J.S.B. and M.-M.M. designed the experimental setup. J.S.B. and S.A.B. performed the experiments; J.S.B. analyzed the data; J.S.B., M.-M.M. and T.L. wrote the article; Ø.F. contributed as an advisor throughout.

Funding: J.S.B. was supported by the Norwegian Research Council, Grant No. 257901 and Gassco Inc., Norway, Grant No. PO 4500024195.

Acknowledgments: The authors would like to acknowledge technical support from Gisle Kleppe and Gunnar Thuestad. Support from Gunnar Birkeland, Uni Research Polytec, Terje Øverland and Kjell Erik Kleveland, PDS Protek, in realizing the project is also appreciated. The suggestions from the anonymous reviewers for improving the manuscript are highly appreciated.

Conflicts of Interest: The authors declare no conflict of interest.

\section{References}

1. U.S. Chemical Safety and Hazard Investigation Board. Investigation Report Executive Summary. In Drilling Rig Explosion and Fire at the Macondo Well, Report No. 2010-10-I-OS; U.S. Chemical Safety and Hazard Investigation Board: Washington, DC, USA, 2010.

2. Kletz, T. What Went Wrong? In Case Histories of Process Plant Disasters and How They Could Have Been Avoided, 5th ed.; Institution of Chemical Engineers: London, UK, 2009; ISBN 13:978-1-85617-531-9.

3. Murray, J.A.; Sander, L.C.; Wise, S.A.; Reddy, C.M. Gulf of Mexico Research Initiative 2014/2015 Hydrocarbon Intercalibration Experiment: Description and Results for SRM 2779, Gulf of Mexico Crude Oil and Candidate SRM 2777 Weathered Gulf of Mexico Crude Oil; NISTIR 8123; National Institute of Standards and Technology: Gaithersburg, MD, USA, 2016.

4. Norsk Standard. Technical Safety, NORSOK Standard, 4th ed.; Standard No. S-001; Norsk Standard: Lysaker, Norway, 2008; 62p.

5. Bjørge, J.S.; Metallinou, M.M.; Log, T.; Frette, Ø. Method for Measuring Cooling Efficiency of Water Droplets Impinging onto Hot Metal Discs. Appl. Sci. 2018, 8, 953. [CrossRef]

6. Leidenfrost, J.G. On the Fixation of Water in Diverse Fire. Int. J. Heat Mass Transf. 1966, 9, 1153-1166. [CrossRef]

7. Liang, G.; Mudawar, I. Review of drop impact on heated walls. Int. J. Heat Mass Transf. 2017, 106, 103-126. [CrossRef]

8. Bernardin, J.D.; Mudawar, I. The Leidenfrost point: Experimental Study and Assessment of Existing Models. J. Heat Transf. 1999, 121, 894-903. [CrossRef]

9. Fukuda, S.; Kohno, M.; Tagashira, K.; Ishihara, N.; Hidaka, S.; Takata, Y. Behavior of small droplet impinging on a hot surface. Heat Transf. Eng. 2014, 35, 204-211. [CrossRef]

10. Lee, C.H.; Kim, D.Y.; Kim, H.D.; Kim, K.C. Dynamic behavior and micro-explosion characteristics of impinging droplets on a high-temperature surface. J. Vis. 2015, 18, 59-70. [CrossRef]

11. Gradeck, M.; Seiler, N.; Ruyer, P.; Maillet, D. Heat Transfer for Leidenfrost drops bouncing onto a hot surface. Exp. Therm. Fluid Sci. 2013, 47, 14-25. [CrossRef]

12. Pasandideh-Fard, M.; Aziz, S.D.; Chandra, S.; Mostaghimi, J. Cooling effectiveness of a water droplet impinging on a hot surface. Int. J. Heat Fluid Flow 2001, 22, 201-210. [CrossRef]

13. Birdi, K.S.; Vu, D.T.; Winter, A. A study of the evaporation rates of small water drop placed on a solid surface. J. Phys. Chem. 1989, 93, 3702-3703. [CrossRef]

14. Misyura, S.Y.; Morozov, V.S. Nonisothermal Evaporation of Layers of Aqueous Salt Solutions. J. Heat Transf. 2018, 141, 1-9. [CrossRef]

15. Zhou, X.; Zhou, B.; Jin, X. Study of fire-extinguishing performance of portable water-mist fire extinguisher in historical buildings. J. Cult. Herit. 2010, 11, 392-397. 
16. Bhatt, N.H.; Pati, A.R.; Kumar, A.; Behera, A.; Munshi, B.; Mohapatra, S.S. High mass flux spray cooling with additives of low specific heat and surface tension: A novel process to enhance the heat removal rate. Appl. Therm. Eng. 2017, 120, 537-548. [CrossRef]

17. Benedetto, A.D.; Cammarota, F.; Sarli, V.D.; Salzano, E. Effect of Diluents on Rapid Phase Transition of Water Induced by Combustion. Am. Inst. Chem. Eng. 2012, 58, 2810-2819. [CrossRef]

18. Log, T. Water Droplets Evaporating on Horizontal Semi-infinite Solids at Room Temperature. Appl. Therm. Eng. 2016, 93, 214-222. [CrossRef]

19. Chang, H. The myth of the boiling point. Sci. Prog. 2008, 91, 219-240. [CrossRef]

20. Chatzikyriakou, D.; Walker, S.P.; Hewitt, G.F.; Narayanan, C.; Lakehal, D. Comparison of measured and modelled droplet-hot wall interactions. Appl. Therm. Eng. 2009, 29, 1398-1405. [CrossRef]

21. Wachters, L.H.J.; Bonne, H.; Van Nouhuis, H.J. The heat transfer from a hot horizontal plate to sessile water drops in the spherodial state. Chem. Eng. Sci. 1966, 21, 923-936. [CrossRef]

22. Misyura, S.Y. The effect of weber number, droplet sizes and wall roughness on crisis of droplet boiling. Exp. Therm. Fluid Sci. 2017, 84, 190-198. [CrossRef]

23. Biance, A.L.; Chevy, F.; Clanet, C.; Lagubeau, G.; Quéré, D. On the elasticity of an inertial liquid shock. J. Fluid Mech. 2006, 554, 47-66. [CrossRef]

24. Cui, Q.; Chandra, S.; McCahan, S. The effect of dissolving gases or solids in water droplets boiling on a hot surface. J. Heat Transf. 2001, 123, 719-728. [CrossRef]

25. Huang, C.K.; Carey, V.P. The effects of dissolved salt on the Leidenfrost transition. Int. J. Heat Mass Transf. 2007, 50, 269-282. [CrossRef]

(C) 2019 by the authors. Licensee MDPI, Basel, Switzerland. This article is an open access article distributed under the terms and conditions of the Creative Commons Attribution (CC BY) license (http://creativecommons.org/licenses/by/4.0/). 